\title{
A Review of the Phytochemistry and Pharmacological Activities of Raphani Semen
}

\author{
Tung-Ting Sham, ${ }^{1}$ Ailsa Chui-Ying Yuen, ${ }^{1,2}$ Yam-Fung Ng, Chi-On Chan, ${ }^{3,2}$ \\ Daniel Kam-Wah Mok, ${ }^{1,2}$ and Shun-Wan Chan ${ }^{1,2,3}$ \\ ${ }^{1}$ Department of Applied Biology and Chemical Technology, The Hong Kong Polytechnic University, Hong Kong \\ ${ }^{2}$ State Key Laboratory of Chinese Medicine and Molecular Pharmacology, 518057 Shenzhen, China \\ ${ }^{3}$ Food Safety and Technology Research Centre, Department of Applied Biology and Chemical Technology, \\ The Hong Kong Polytechnic University, Hong Kong
}

Correspondence should be addressed to Daniel Kam-Wah Mok; bcdaniel@polyu.edu.hk and Shun-Wan Chan; bcswchan@polyu.edu.hk

Received 3 February 2013; Revised 9 May 2013; Accepted 23 May 2013

Academic Editor: Muhammad Nabeel Ghayur

Copyright (c) 2013 Tung-Ting Sham et al. This is an open access article distributed under the Creative Commons Attribution License, which permits unrestricted use, distribution, and reproduction in any medium, provided the original work is properly cited.

The dried ripe seed of Raphanus sativus L., commonly known as radish seed (or Raphani Semen), is used as traditional Chinese medicine (TCM) to treat constipation, chronic tracheitis, and hypertension. The major active compounds in Raphani Semen are alkaloids, glucosinolates, brassinosteroids, and flavonoids. Fatty acids are its main nutritional contents. Raphani Semen has been demonstrated to have beneficial effects on hypertension, obesity, diabetes mellitus, constipation, and cough. So far, there is no report about the adverse/toxic effects of this herb on humans. However, Raphani Semen processed by roasting was reported to exhibit some adverse effects on mice. Additionally, erucic acid, the main fatty acid in Raphani Semen, was shown to enhance the toxicity of doxorubicin. Thus, Raphani Semen has a potential risk of causing toxicity and drug interaction. In summary, Raphani Semen is a valuable TCM herb with multiple pharmacological effects. More studies on Raphani Semen could help better understand its pharmacological mechanisms so as to provide clear scientific evidence to explain its traditional uses, to identify its therapeutic potential on other diseases, and to understand its possible harmful effects.

\section{Introduction}

Raphanus sativus L. belongs to the family Brassicaceae (Cruciferae, an older name). It is known as Radish in English, Daikon in Japanese, and "Laifu" or "Luobo" in Chinese. With its high adaptive ability, high yield, and abundant nutritional value, Raphanus sativus $\mathrm{L}$. has long been grown as a food crop worldwide, especially in China, Japan, Korea, and Southeast Asia [1]. The leaf, seed, and root of Raphanus sativus L. are claimed to have various medicinal uses [2], but only its dried ripe seed (Raphani Semen, Figure 1) is listed in Pharmacopoeia of the People's Republic of China (CP) [3]. Raphani Semen is commonly used in traditional Chinese medicine (TCM) for promoting digestion, relieving distention, directing "Qi" downward, and dissipating phlegm.
Traditionally, it is used to treat food dyspeptic retention, distending pain in the epigastrium and abdomen, constipation, diarrhea and dysentery, panting, and cough with phlegm congestion clinically in combination with other TCM herbs $[3,4]$. For example, Raphani Semen is one of the three important ingredients of San-Zi-Yang-Qin-Tang, which is a common TCM formula for relieving cough and asthma, dissipating phlegm, and promoting digestion [5].

Raphani Semen is usually called "Laifuzi" or "Luobozi" in Chinese. Its use in TCM can be traced back to 900s A.D. in Ri-Hua-Zi-Zhu-Jia-Ben-Cao $[3,6]$. The medical use of Raphanus sativus L. was even much earlier than that of Raphani Semen. It was recorded in Ming-Yi-Bie-Lu in 3-4 A.D [6]. Although the history of using Raphani Semen for medicinal purposes has more than a thousand years and it 


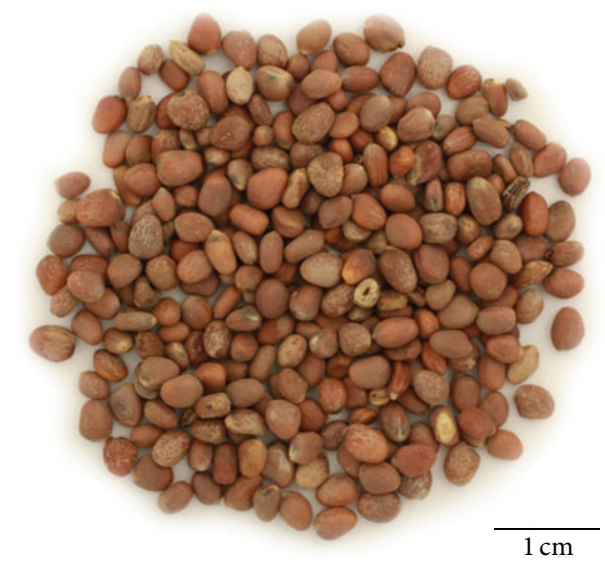

Figure 1: The dried seeds of Raphanus sativus L.

is one of the herbs documented in $\mathrm{CP}$, there is no comprehensive review on the phytochemistry and pharmacology of Raphani Semen.

With the advancement of analytical chemistry and pharmacology as well as the increase in the popularity of using natural products as an alternative medicine for treating chronic diseases such as cardiovascular diseases and cancer, research findings related to natural products expanded exponentially in recent decades [7-11]. This review summarized the recent scientific findings of Raphani Semen's phytochemistry and pharmacological activities, such as antihypertensive effect and other beneficial effects on digestive and respiratory systems, so as to provide a comprehensive overview of this herb.

\section{Bioactive Chemical Constituents of Raphani Semen}

Raphani Semen was found to have various classes of active compounds $[2,12]$, for instance, alkaloids, glucosinolates, brassinosteroids, and flavonoids. In fact, most of these phytochemicals have been shown to have different bioactivities (Tables 1, 3, and 4).

2.1. Alkaloids. The total alkaloid content (in terms of sinapine thiocyanate equivalent) of Raphani Semen was found to range from $1.056 \%$ to $2.620 \%$ (weight percent) [13]. Watersoluble alkaloids of Raphani Semen demonstrated to have antihypertensive effects, which would be elucidated in the section of pharmacological effects in this review. Sinapine is a natural phenolic amine commonly found in the seeds of brassica (or cruciferous) plants $[14,15]$. Sinapine is the major bioactive alkaloid [16], existing in the form of sinapine thiocyanate in Raphani Semen $[17,18]$. In CP, the content of sinapine thiocyanate is used for the quality control of Raphani Semen. Previous studies have suggested that sinapine had antidiarrheal, anti-inflammatory [19], radioprotective [20, 21], neuroprotective [22], antioxidative [23], and antiaging effects [24]. Additionally, sinapine was shown to have potential in treating Alzheimer's disease by inhibiting the cerebral acetylcholinesterase activity $[25,26]$.

2.2. Glucosinolates and Isothiocyanates. Apart from sinapine, another group of well-known secondary product found in brassica plants is glucosinolates. Glucosinolates are stable compounds found in plant tissues. They carry no specific function. Generally, they would be transformed to other forms with higher bioactivity [69]. When intact cells of brassica plants are disrupted, glucosinolates are hydrolyzed by myrosinase or gut bacteria to form a series of products, such as isothiocyanate, thiocyanate, and nitriles [70, 71].

In dried Raphani Semen, total glucosinolate content was found to be $73.504 \pm 0.980 \mu \mathrm{mol} / \mathrm{g}$. Among the glucosinolates in Raphani Semen, the content of glucoraphenin $(40.338 \pm 0.025 \mu \mathrm{mol} / \mathrm{g})$ is remarkably higher than glucoraphanin $(0.762 \pm 0.026 \mu \mathrm{mol} / \mathrm{g})$ [72]. Glucoraphanin was reported to be the modulator of hepatic cytochrome P450 and phase II conjugation activities in an in vitro study [29]. It may contribute to the chemopreventive activity of brassica vegetables.

Isothiocyanates, which are one type of the principal products of glucosinolates, were reported to be able to suppress tumour cell growth [73, 74]. Sulforaphane [27] and sulforaphene [42] are isothiocyanates derived from glucoraphanin and glucoraphenin, respectively. The content of sulforaphane and sulforaphene in Raphani Semen are 77.19$89.19 \mu \mathrm{g} / \mathrm{g}$ [75] and $7 \mathrm{mg} / \mathrm{g}$ [30], respectively. The hydrolysis of glucoraphanin to sulforaphane [27] is shown in Figure 2. Sulforaphene was first identified via the investigation of antibacterial test with water extract of Raphani Semen [42] and later also found to possess growth inhibitory effect on human immortalized hepatocytes, to the similar extent as sulforaphane [39]. These two isothiocyanates were also found to have potentials in other chemoprevention of various cancers $[1,28,31,33-35,37,38,40,41]$. In particular, sulforaphane was reported to be the potent inducer of phase II antioxidant enzymes $[76,77]$ implicated in carcinogen detoxification. Using molecular docking technique, sulforaphane was shown to bind to human serum albumins via nonpolar amino acids so as to deliver sulforaphane derived from glucoraphanin to target tissues [78]. The interaction of sulforaphane with serum albumins may give hints to the mechanism of actions of glucoraphanin or sulforaphane intake in cancer therapy.

2.3. Brassinosteroids. Brassinosteroids represent a class of steroidal phytohormones showing high growth promoting activity in plants [79, 80]. Four kinds of brassinosteroids isolated from Raphani Semen are teasterone, 28homoteasterone, brassinolide, and castasterone [81, 82]. A recent report provided the first evidence that natural brassinosteroids at micromolar concentrations could inhibit the growth of several human cancer cell lines without affecting the growth of normal cells [43]. The study suggested that castasterone showed significant growth inhibitory effect of some cancer cells but brassinolide did not. However, teasterone and castasterone represented biogenetic precursors of 


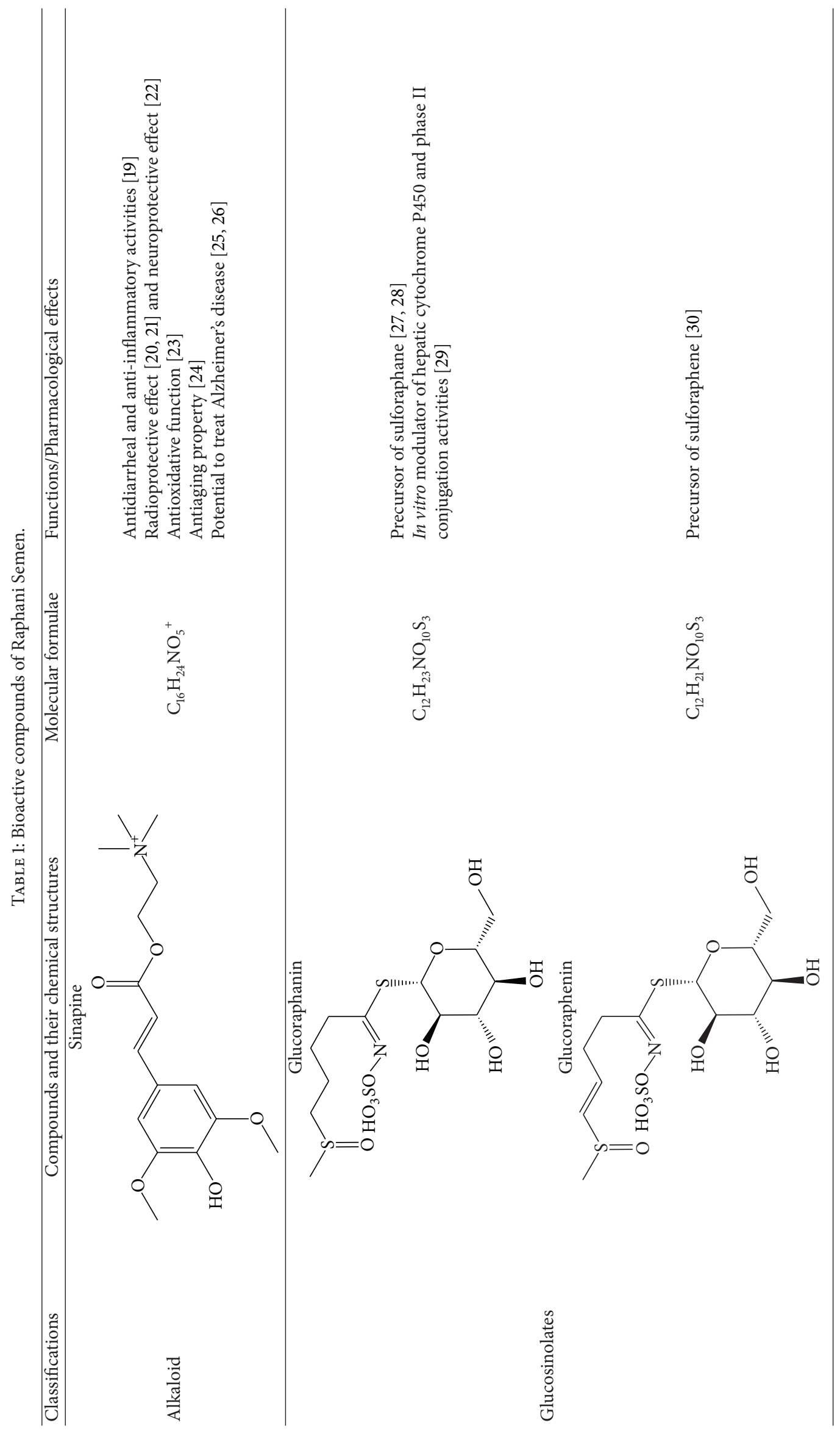




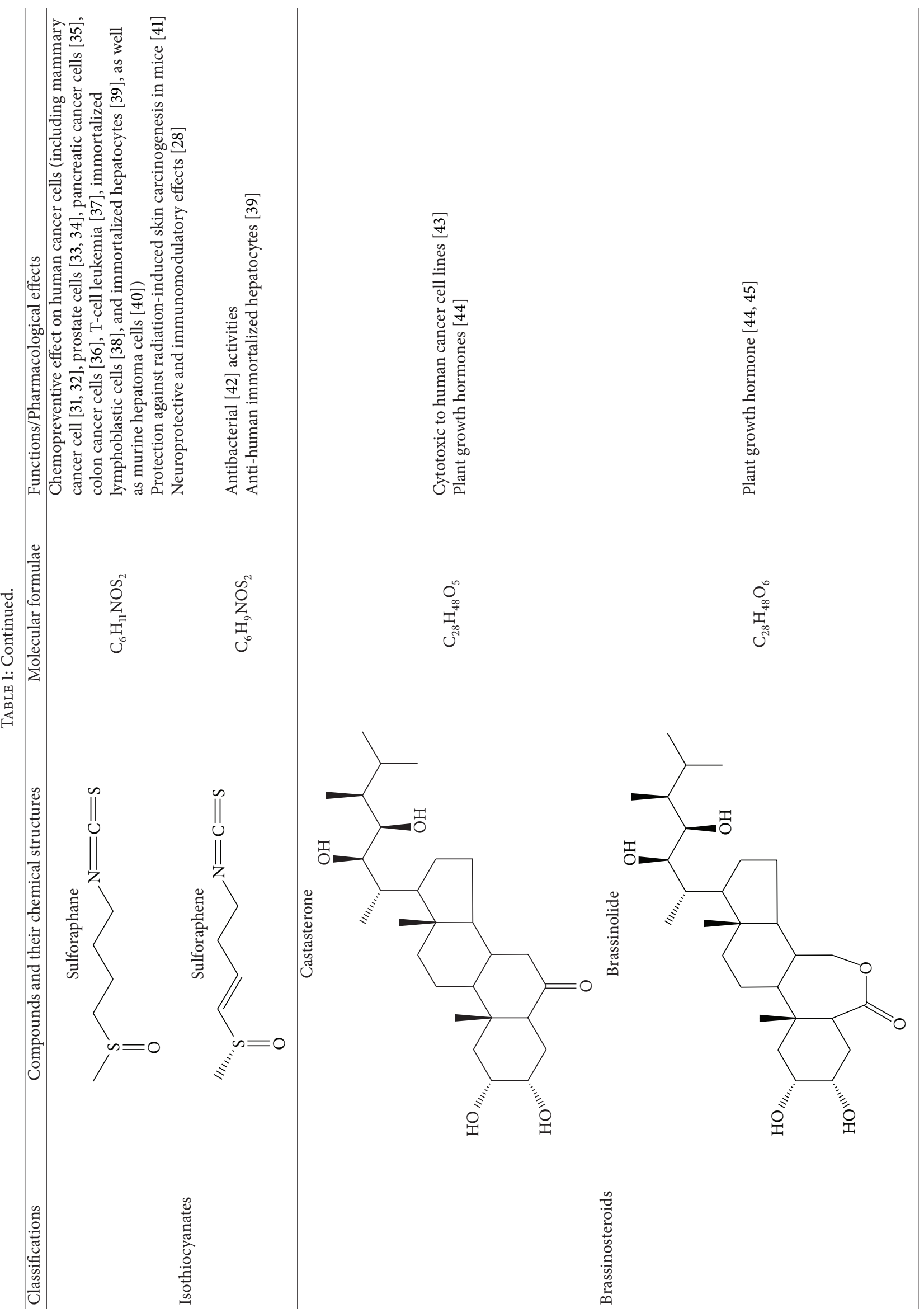




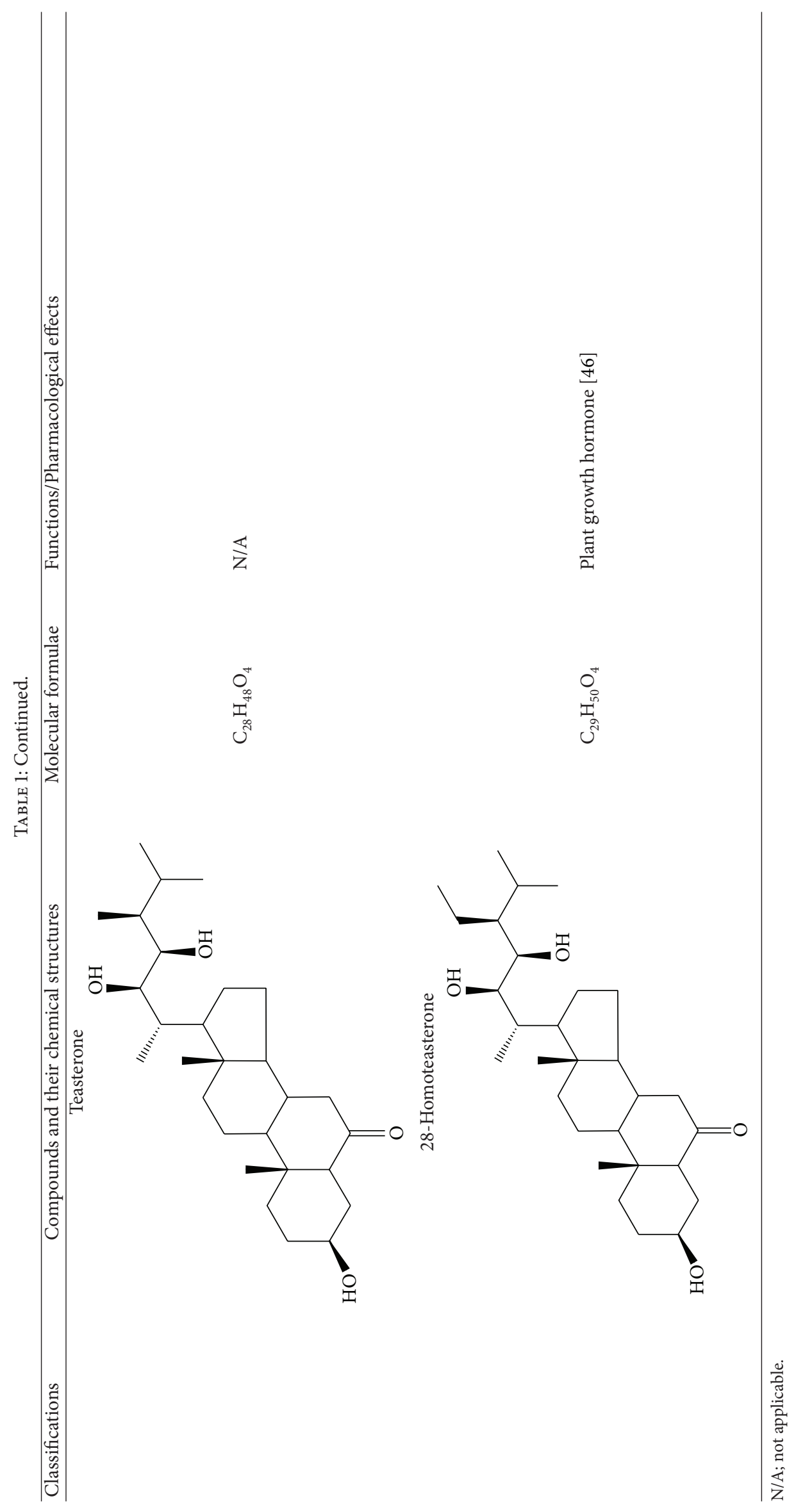


TABLE 2: Nutritional ingredients identified in Raphani Semen.

\begin{tabular}{lcccc}
\hline Classifications & \multicolumn{3}{c}{ Nutritional ingredients } \\
\hline $\begin{array}{l}\text { Fatty acids } \\
{[47-51]^{\#}}\end{array}$ & $\begin{array}{c}\text { Linolenic acid } \\
\text { Stearic acid }\end{array}$ & $\begin{array}{c}\text { Erucic acid } \\
\text { Arachidic acid }\end{array}$ & $\begin{array}{c}\text { Oleic oil } \\
\text { Behenic acid }\end{array}$ & $\begin{array}{c}\text { Eicosenoic acid } \\
\text { 15-Tetracosanoic acid }\end{array}$ \\
\hline $\begin{array}{l}\text { Tocopherol } \\
\text { isomers [51] }\end{array}$ & $\alpha$-Tocopherol & $\beta$-Tocopherol & $\gamma$-Tocopherol & $\delta$-Tocopherol \\
\hline Minerals [51] & Calcium & Magnesium & Iron & Zinc \\
Proteins & Rs-AFP1 [52, 53] & Rs-AFP2 [52, 54] & RAP-1 [55] & RAP-2 [55] \\
\hline $\begin{array}{l}\text { Polysaccharides } \\
(12.73 \%) ~[56]\end{array}$ & L-arabino-D-galactan [57] & $\begin{array}{c}\text { L-arabino-D-galactan- } \\
\text { containing proteoglycan } \\
{[57]}\end{array}$ & & 2 albumins [52] \\
\hline
\end{tabular}

\#Details are shown in Table 3.

\# Details are shown in Table 4.

brassinolide $[81,83]$. It is essential to isolate these compounds from the seeds to further identify their bioactivities.

2.4. Flavonoids. The total flavonoids (in terms of rutin content) in Raphani Semen were determined to be $0.60 \%$ [56]. Those flavonoids have been reported to have in vitro angiotensin converting enzyme (ACE) inhibitory activity through binding to the $\mathrm{Zn}^{2+}$ ion located at the active site of ACE [84].

\section{Nutritional Contents in Raphani Semen}

Radish is an important food crop; thus there are studies examining the nutritional ingredients of Raphani Semen. Fatty acids are the major nutritional composition of interests in Raphani Semen. Other nutritional components include minerals, vitamin, proteins, and polysaccharides.

3.1. Fatty Acids. Several studies have investigated the fatty acid composition in the oil of Raphani Semen [47-51]. The yield of its oil extracted by Soxhlet extraction was found to about $35 \%$ of its dry weight. The extraction yield could be up to $42.64 \pm 1.36 \%$, depending on the growing areas of Raphani Semen used. Many types of common fatty acids, including linolenic acid, erucic acid, oleic oil, eicosenoic acid, palmitic acid, stearic acid, arachidic acid, behenic acid, and 15-tetracosenoic acid, were identified using gas chromatography. Unsaturated fatty acids were found to account for over $80 \%$ of the total fatty acids. Linolenic acid, erucic acid, and oleic oil were the main fatty acids detected [47]. Oil of Raphani Semen was revealed to have significant antioxidative activity in the ferric reducing antioxidant power assay [47]. Additionally, linolenic acid was found to attenuate the formation of atherosclerotic plaques in rats fed with highlipid diet through improving the antioxidation capacity of the body [59]. In a clinical trial, linolenic acid was revealed to be effective in improving the lipid profiles of 106 people with hyperlipidemia by taking soft capsules containing both $\alpha$-linolenic acid and $\gamma$-linolenic acid [60]. Although the development of cardiovascular disease is multifactorial, hypercholesterolemia is believed to play a crucial role in its pathogenesis and progression [85]. Raphani Semen, which contains high content of linolenic acid, may have effects on reducing the risk of cardiovascular diseases.

3.2. Minerals. Minerals, which are trace elements, are directly involved in human metabolism. There is growing interest in the role of certain minerals in physiological processes [86]. Investigation on the mineral content in Raphani Semen is scarce. There was a study analyzing calcium, magnesium, zinc, and iron contents in the oil of Raphani Semen by using Inductively Coupled Plasma-Optical Emission Spectrometry [51]. Calcium was found to be the highest in content. The mineral contents of Raphani Semen are listed in Table 2.

3.3. Tocopherol Isomers. Tocopherols are one type of vitamin E homologues. Raphani Semen contains $\alpha_{-}^{-}, \beta-, \gamma^{-}$, and $\delta$-tocopherols [51], among which $\gamma$-tocopherol content is the highest $(233 \pm 6.63 \mu \mathrm{g} / \mathrm{g})$. Their contents and chemical structures are shown in Table 4 . Tocopherols are important antioxidant compounds in oils. The oxidative stability of Raphani Semen oil mostly relied on the presence of tocopherols [67].

3.4. Proteins. Four purified antifungal proteins and one class of antifungal albumins were distinguished from Raphani Semen. They are Raphanus sativus antifungal proteins RAP-1, RAP-2 [55], Rs-AFP1 [52, 53], Rs-AFP2 [52, 54], and radish $2 S$ storage albumins [52]. All purified antifungal proteins showed an inhibitory effect against Botrytis cinerea in the low ionic strength growth medium. On the other hand, RAP-1 exhibited stronger growth inhibitory activities against yeast Candida albicans and Saccharomyces cerevisiae than RAP-2. Rs-AFP1 and Rs-AFP2 are composed of highly basic $5 \mathrm{kDa}$ polypeptides which are assembled in an oligomeric quaternary configuration with a high degree of specificity to filamentous fungi. The antifungal activity of Rs-AFP2 $\left(\mathrm{IC}_{50}\right.$ values $=0.4-25 \mu \mathrm{g} / \mathrm{mL})$ is much more potent than Rs-AFP1 $\left(\mathrm{IC}_{50}\right.$ values $\left.=0.3-100 \mu \mathrm{g} / \mathrm{mL}\right)$. Radish $2 \mathrm{~S}$ storage albumins consist of at least five isoforms. They have significant growth inhibitory effect on various plant pathogenic fungi and some bacteria when assayed in the low ionic strength medium. 


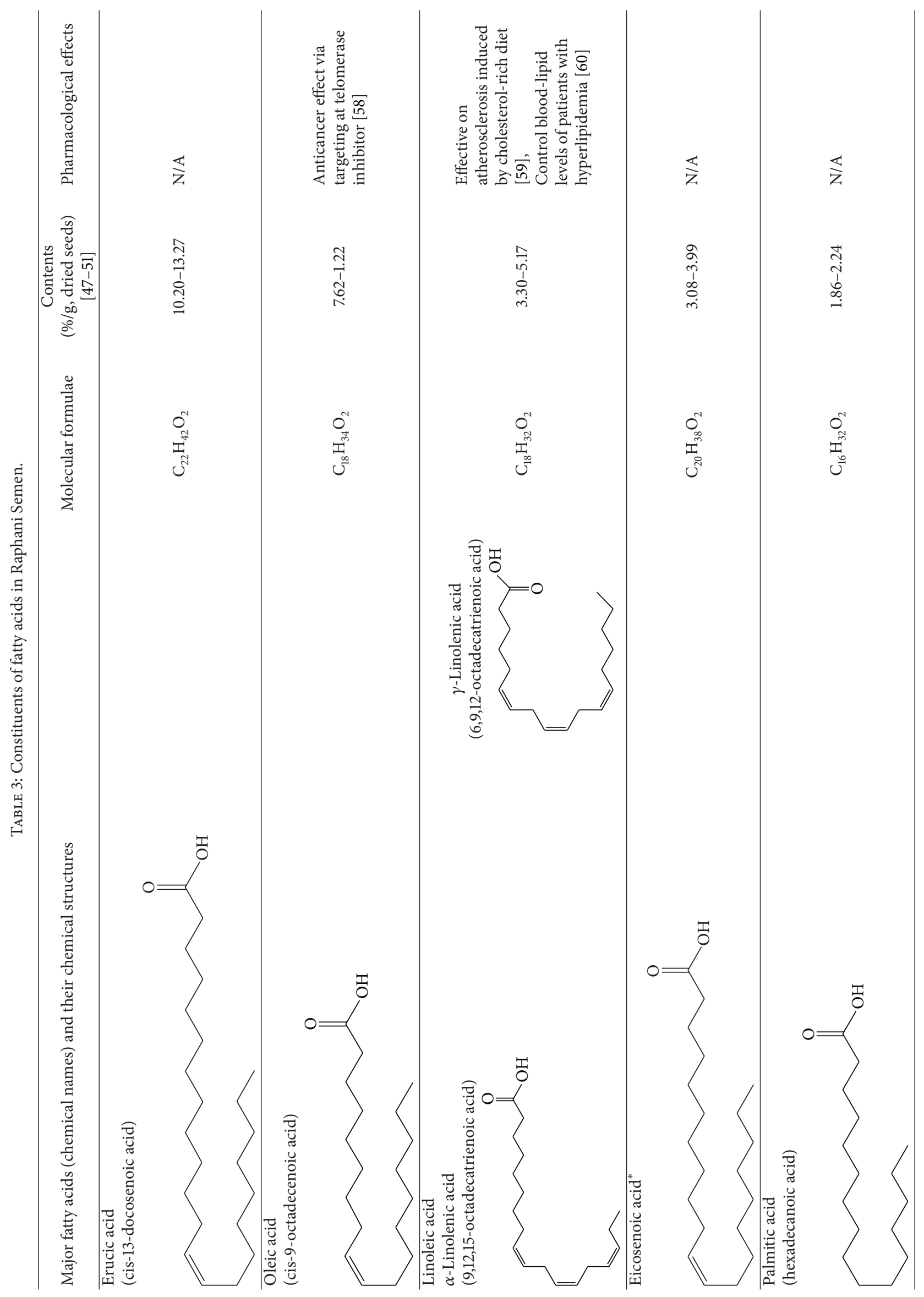




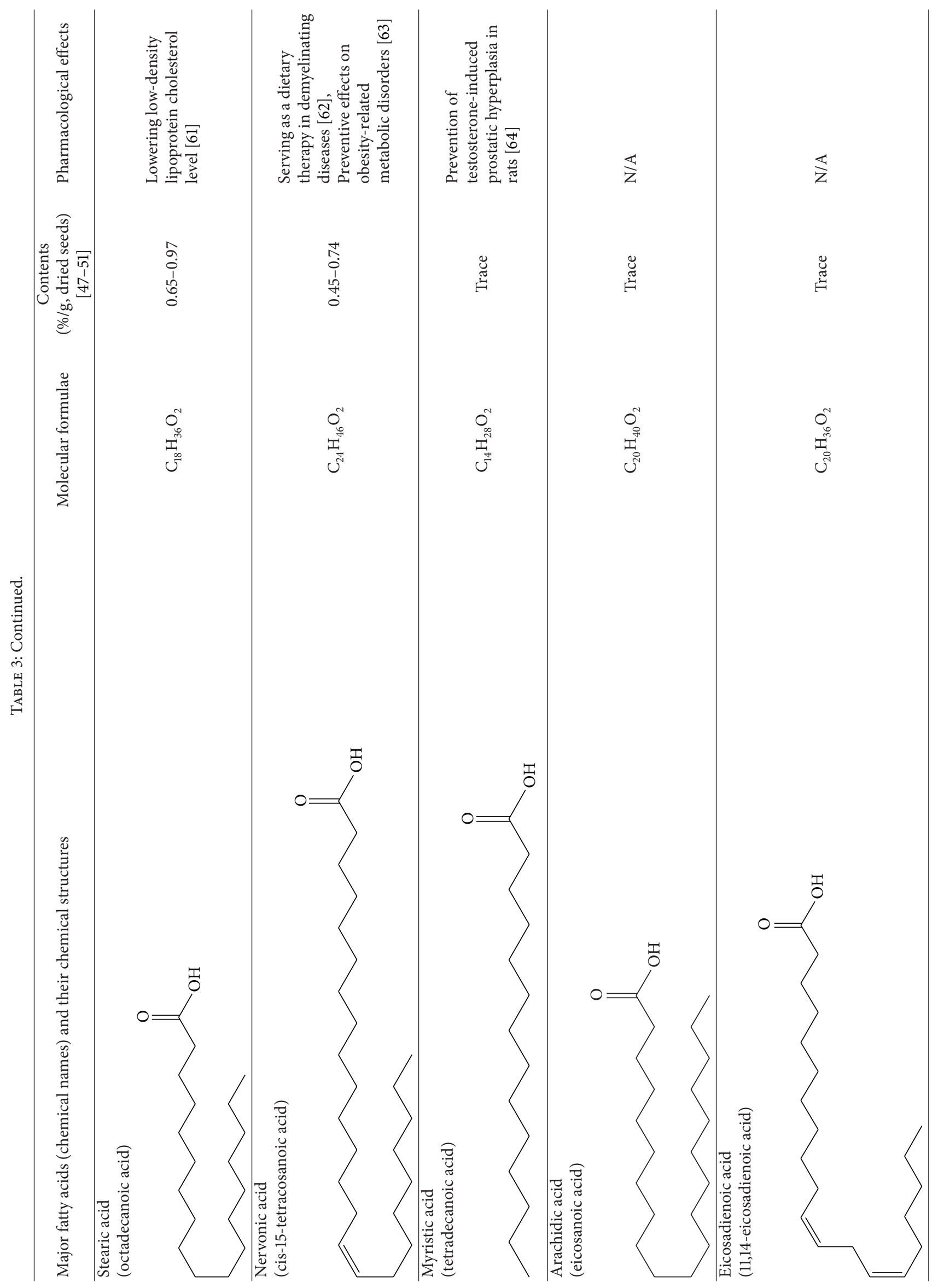




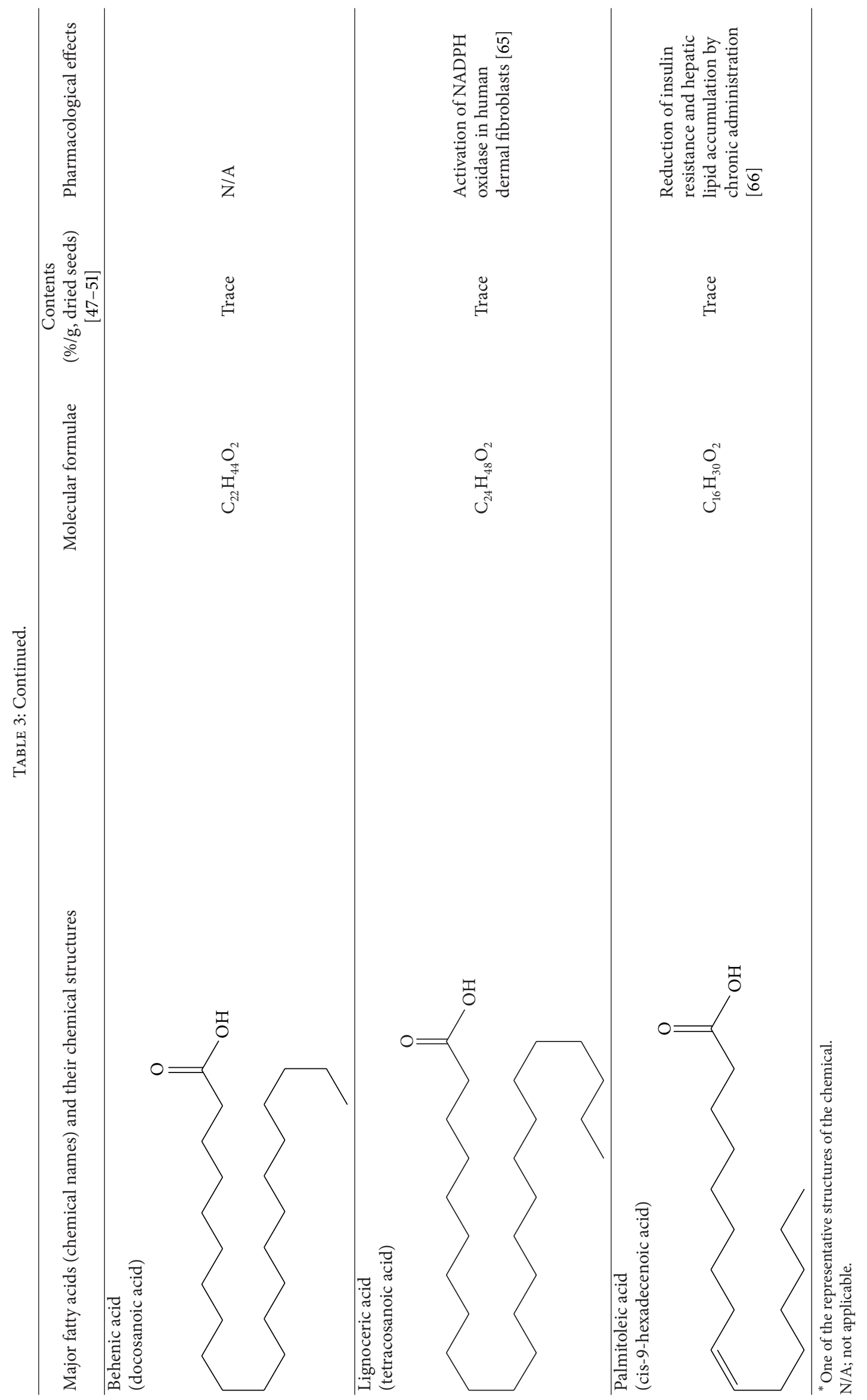


TABLE 4: Constituents of tocopherol isomers identified in Raphani Semen [51].

\begin{tabular}{|c|c|c|c|}
\hline Tocopherol isomers and their chemical structures & $\begin{array}{c}\text { Molecular } \\
\text { formulae }\end{array}$ & $\begin{array}{c}\text { Contents } \\
(\mu \mathrm{g} / \mathrm{g}, \text { dried seeds })\end{array}$ & $\begin{array}{l}\text { Functions/Pharmacological } \\
\text { effects }\end{array}$ \\
\hline \multicolumn{4}{|l|}{$\alpha$-Tocopherol } \\
\hline $\mathrm{HO}^{-}$ & $\mathrm{C}_{29} \mathrm{H}_{50} \mathrm{O}_{2}$ & $12.22 \pm 0.10$ & $\begin{array}{l}\text { Antioxidation }[51,67] \\
\text { Reduction of the effect of } \\
\text { cadmium in the liver and } \\
\text { brain of Wistar rats }[68]\end{array}$ \\
\hline
\end{tabular}

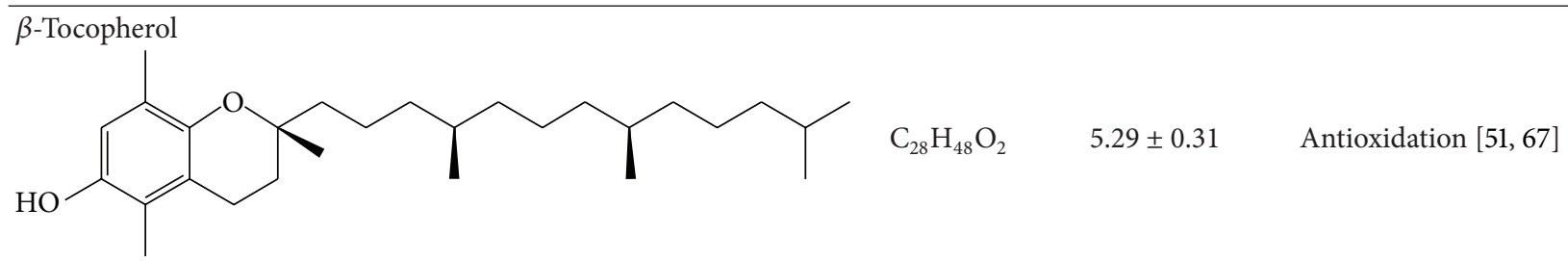

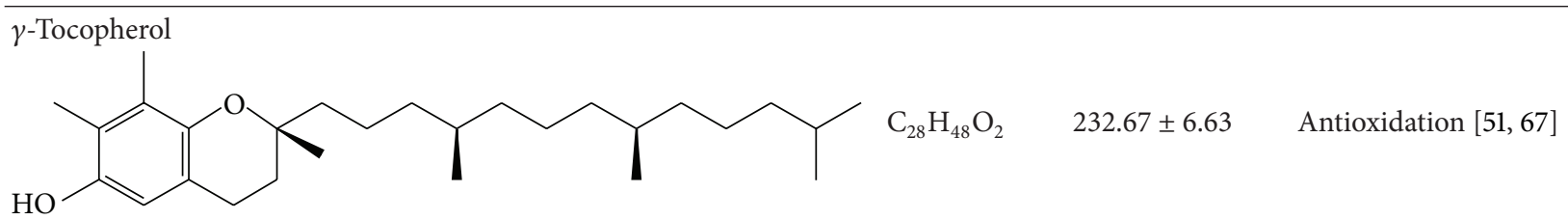

$\delta$-Tocopherol<smiles>Cc1cc(O)cc2c1O[C@](C)(CCC[C@@H](C)CCC[C@@H](C)CCCC(C)C)CC2</smiles><smiles></smiles>

Glucoraphanin

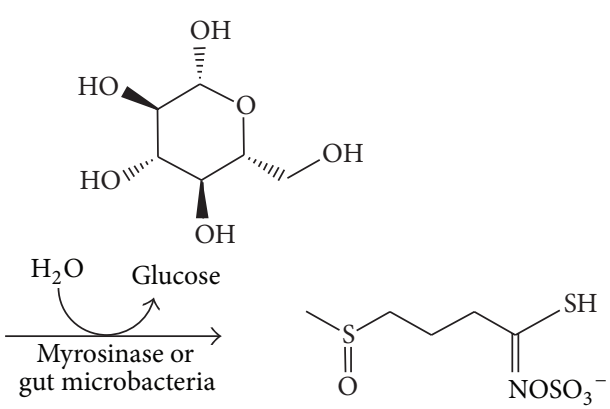
gut microbacteria

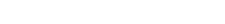<smiles></smiles>

Sulforaphane

FIGURE 2: The hydrolysis process of sulforaphane from glucoraphanin by myrosinase or gut microbacteria.

\section{Pharmacological Activities of Raphani Semen}

The extracts from Raphani Semen in different solvents were studied extensively. The pharmacological functions of Raphani Semen include antihypertensive effect, antilipase activity, improvement of the pathologic insulin resistance state, gastrointestinal effect, treatment of constipation, and antitussive therapeutic effect.

4.1. Antihypertensive Effect. The increase in blood pressure could raise the risks of myocardial infarction, heart failure, stroke, end-stage renal disease, peripheral vascular disease, and mortality from all causes [87]. In randomized clinical trials, antihypertensive therapy has also resulted in reductions in the incidence of stroke, myocardial infarction, and heart failure [88]. Thus, the development of treatment of hypertension attracted lots of research studies. The antihypertensive effect of Raphani Semen has been investigated in both preclinical and clinical settings in the past two decades.

The renin-angiotensin system is a hormone system that regulates blood pressure and water fluid balance, but it also participates in the pathophysiology of myocardial infarction, diabetic nephropathy, and congestive heart failure. ACE is one of the key therapeutic targets for the regulation of these pathophysiological developments. The ethanol extract 
of Raphani Semen was found to possess both in vitro ACE inhibitory and antioxidant activities. Thus, it could be used to treat hypertension, prevent or slow down the progression of cardiovascular and any free radical-related disorders. The presence of high phenolic and flavonoid contents in Raphani Semen extract would be a major contributor towards ACE inhibition through binding to $\mathrm{Zn}^{2+}$ at the active site of ACE [84]. Further in vivo studies on the effects of Raphani Semen on the renin-angiotensin system could give more insights on its anti-hypertensive effects.

The bioactive fractions, such as octenal, dibutyl phthalate, sinapine bisulfate, water-soluble alkaloids, and n-butanol extract, were found to have remarkable effects on lowering blood pressure $[89,90]$. Systolic blood pressure of spontaneously hypertensive rats (SHR) measured by tail-cuff method decreased after treating the animals with high dosage of n-butanol extract of Raphani Semen [89]. The pharmacological mechanism of Raphani Semen's blood pressure lowering effect may be brought about by its vasodilation function to reduce the vascular resistance in the blood vessels [91]. Raphani Semen water extract exhibited blood pressure and heart rate reductions by mediating an atropinesensitive pathway after being administrated to anaesthetized normotensive rat intravenously [92]. Such extract could also dose-dependently inhibit both atrial contractile force and rate of contraction in guinea-pig-isolated atria, where the inhibitory effect observed was found to be mediated through activation of muscarinic receptors [92].

Water-soluble alkaloids from Raphani Semen were demonstrated to have prominent hypotensive function by significantly enhancing serum nitric oxide (NO) content and cardiac nitric oxide synthase (NOS) activity in SHR [90]. Through decreasing serum malondialdehyde content and enhancing superoxide dismutase activity in vivo, Raphani Semen alkaloids are believed to have good cardiovascular protective effects from oxidative damage. In addition, choline, a metabolite from the degradation of sinapine in Raphani Semen extract in the digestive system, might activate the NO-NOS system [90], thereby increasing the synthesis of $\mathrm{NO}$ and resulting in vasodilation [9]. However, whether the anti-hypertensive effect of water-soluble alkaloids from Raphani Semen resulted from the increase in NO availability by directly enhancing NO production (stimulation of NOS activity), by indirectly reducing NO degradation (antioxidant properties), or by both pathways was currently unknown and warranted further investigations.

Raphani Semen has been used clinically in China. A proprietary drug called Qingxuanjianyia tablet is sold in China mainly containing concentrated Raphani Semen water extract in which sinapine is the key bioactive compound. It is used to treat hypertension. In a clinical trial, 160 hypertensive patients were randomly divided into four groups and orally administrated with Qingxuanjianyia tablets, nifedipine, captopril, or atenolol for 30 days [93]. The results indicated that intake of Qingxuanjianyia tablets could lower $82.5 \%$ of patients' blood pressure and ranked the third among the four tested medicines. There was no significant change on the heart rate as well as obvious side effects [93]. Another study with the same tablet compared to nifedipine showed similar results and suggested that Qingxuanjianyia tablet was suitable to mild and moderate hypertensive patients [94].

4.2. Antilipase Activity. Inhibition of pancreatic lipase is one of the potential approaches for the treatment of obesity. Pancreatic lipase is the main lipid-digesting enzyme to remove fatty acids from the $\alpha$ and $\alpha^{\prime}$ positions of dietary triglycerides to yield their lipolytic products and $\beta$-monoglyceride as well as long-chain saturated and polyunsaturated fatty acids [95]. The methanol extracts of Raphani Semen and 36 other Chinese medicinal herbs were tested for their effects on inhibiting porcine pancreatic lipase (PPL, type II) in vitro. Although Raphani Semen demonstrated a relatively weak inhibitory activity against PPL as compared with other herbs such as the dried fruit-spike of Prunella vulgaris L. and the rhizome of Rheum palmatum L. [96], it could significantly suppress the activity of pancreatic lipase in vivo. Additionally, Raphani Semen carries fatty acids (linolenic acid [59, 60], stearic acid [61], nervonic acid [62], and palmitoleic acid [66]) which have been shown to have beneficial effect on obesity-related disorders. Therefore, Raphani Semen might have antiobesity effect.

4.3. Improvement of Insulin Resistance. Patients with type 2 diabetes mellitus tend to develop hypertension, which is a major cause of cardiovascular morbidity and mortality in this group of patients [97]. Although the exact mechanisms underlying this propensity remain to be clarified, insulin resistance, dysfunction, and structural abnormalities in microvascular system together with renal damage may play crucial roles in the disease progression [98]. Raphani Semen is used to remove phlegm turbidity by TCM practitioners. According to TCM theory, higher phlegm turbidity is believed to be related to increased blood viscosity [99]. In fact, increased blood viscosity is one of the inducers of insulin resistance since it could affect the normal binding capacities of the insulin receptors in vascular system. A research found that intragastric administration of Raphani Semen extract to Sprague-Dawley rats with hypertension and insulin resistance could increase the insulin-binding affinity to its receptors on hepatocytes [99]. Therefore, Raphani Semen may be effective in improving the pathologic insulin resistance state.

4.4. Gastrointestinal Effect. Gastrointestinal (GI) neuromuscular diseases consist of multiple groups of chronic conditions associated with impaired gut motility. Since GI disorders (varying in etiopathogenic mechanisms, pathologic lesions, and regions of GI tract involved) are very common and are considered as one of the major social and economic burdens, they represent a relevant matter for public health [100]. Using natural products to relieve GI disorders becomes a new approach to handle these problems. It was reported that Raphani Semen water extract could enhance the contractility of smooth muscles from guineapig ileum [101]. Another study showed that Raphani Semen water extract exhibits significant in vitro GI prokinetic effects 
in the rabbit jejunum and ileum, rat stomach fundus, and ileum as well as the guinea-pig jejunum [102]. Additionally, Raphani Semen water extract was demonstrated to exhibit in vivo laxative effects in mice [102]. Interestingly, different processing methods on Raphani Semen could affect the strength of gastric emptying effect on Kunming mice. It was found that roasted Raphani Semen elicited less inhibitory effect on the gastric emptying as compared with the dried (no roasting) one [103]. Mice treated with roasted Raphani Semen had $\sim 57 \%$ gastric residue, while mice treated with dried Raphani Semen had $\sim 70 \%$ gastric residue [103]. In contrast, overroasted Raphani Semen could cause stomach swelling as its gastric residue content was up to $80 \%$ (the highest among the three Raphani Semen extract-treated mice) [103]. Comparing to the movement of GI smooth muscle in Kunming mice, ileum smooth muscles of rabbits fed with roasted Raphani Semen extract were much more reactive. Concerning the small intestine propulsive effect, there was no significant difference between the three Raphani Semen extract-treated mice. It could be deduced that food digestion could be enhanced better by the roasted Raphani Semen as it had the ability to retain food in the stomach longer via moderate inhibition of the gastric emptying.

4.5. Treatment of Constipation. Mice's intake of Raphani Semen oil in $2.4 \mathrm{~g} / \mathrm{kg} / \mathrm{day}$, which was equivalent to the amount for human's dosage in TCM, could increase defecation rate (in terms of the number and mean weight of formed fecal pellets excreted) [104]. Additionally, same dosage of Raphani Semen water extract could shorten the defecation latency of constipation and increase the defecation rate [104]. It suggested that both Raphani Semen oil and its water extract could be effective in treating constipation.

4.6. Antitussive Effect. Water extract of Raphani Semen was shown to have cough inhibitory activity on Kunming mice. The antitussive therapeutic effect of the dried Raphani Semen (without roasting) was found to be much longer lasting than those of roasted and overroasted samples, while there was no significant difference in the phlegm-eliminating actions among various groups [105].

\section{Toxicology}

Although many positive effects of Raphani Semen were determined, different processing methods (dried, roasted and overroasted) on Raphani Semen may give different levels of toxicity. A study on the effect of processing methods on Raphani Semen's toxicity showed that Kunming mice fed with roasted Raphani Semen had the highest mortality, dirtier body hair, and more liquid-form feces, while the other two groups fed with dried and overroasted samples had relatively mild adverse responses. The observed abnormalities may be attributed to the chemical changes during the roasting process of Raphani Semen which led to the increased GI movement [103]. Another study assessed the acute toxicity of Raphani Semen cold-water extract on Balb/c mice [92]. No death of animal was observed at the maximum tested oral dose $(10 \mathrm{~g} / \mathrm{kg})$. Additionally, no apparent GI or behavioral side effects were identified during the testing period [92]. The discrepancy in the results of different studies may be attributed to the difference in animal species used, content of active components in Raphani Semen extracts, and extraction methods adopted. Since different processing methods on Raphani Semen could give different levels of toxicity, more attention should be paid when choosing the processing method of Raphani Semen. It is suggested to adopt the standardized simple stir-baking method of the seeds recorded in CP (Appendix II D) [3] so as to ensure the therapeutic efficacy and reduce possible risk of inducing toxicity.

Raphani Semen contains high content of erucic acid. It is a long-chain unsaturated fatty acid. Studies found that erucic acid had adverse effect on heart as erucic acid was poorly oxidized by the mitochondrial $\beta$-oxidation system, especially by the myocardial cells, which resulted in an accumulation of erucic acid, producing myocardial lipidosis [106, 107]. Although the negative effect has not been confirmed in humans, a variety of animal species fed with erucic acid could result in forming myocardial lipidosis in a dosedependent manner. Erucic acid also interacts with other drugs. When applied alone, erucic acid showed no negative effect on survival and cardiac contractility in Wistar albino rats. However, under concomitant use with doxorubicin (a drug used for chemotherapy), erucic acid could enhance the toxicity of doxorubicin [108]. So far, the adverse effects of Raphani Semen consumption due to the presence of erucic acid have not been reported. There are reports on animal studies about induction of myocardial lipidosis occurrences after the consumption of pure or high concentration of erucic acid but not the TCM herb, Raphani Semen. Owing to the multiple pharmacological effects of Raphani Semen and the high content of bioactive compounds such as linolenic acid in Raphani Semen, it is worthwhile to launch more investigations to evaluate the risks and benefits of using Raphani Semen.

\section{Raphani Semen in Perspectives}

Despite the fact that Raphani Semen is commonly used in TCM, there is a lack of in-depth study on the pharmacological effects of its active ingredients. It was found that among the reported pharmacological effects, most of them are related to chronic diseases such as cardiovascular diseases and diabetes mellitus. For the progression of those chronic diseases, reactive oxygen species plays an important role. In view of the abundance of phenolic compounds, flavonoids, and other compounds with high antioxidant power in Raphani Semen, it may be possible to identify new drug candidate or lead compound for treating cardiovascular diseases and diabetes mellitus. Further studies on both pharmacology and chemistry could provide valuable insight into this area.

So far, there is no report about the adverse/toxicity effects of this herb on humans. However, Raphani Semen processed by roasting was reported to exhibit some adverse effects on mice. Additionally, erucic acid, an active compound from Raphani Semen, was shown to enhance the toxicity 
of doxorubicin. Thus, Raphani Semen has a potential risk of causing drug interaction. Since the undesirable effects of Raphani Semen overdosage are still not clearly evaluated, toxicology test is a must to examine its potential harmful effects on normal human cells and experimental animals.

In summary, Raphani Semen is a valuable TCM herb with multiple pharmacological effects. More studies on Raphani Semen should be done for a better understanding of its pharmacological mechanisms so as to provide clear scientific evidence to explain its traditional uses, to identify its therapeutic potential on other diseases, and to understand its possible harmful effects.

\section{Abbreviations}

$\begin{array}{ll}\text { ACE: } & \text { Angiotensin converting enzyme } \\ \text { GI: } & \text { Gastrointestinal } \\ \text { NO: } & \text { Nitric oxide } \\ \text { NOS: } & \text { Nitric oxide synthase } \\ \text { CP: } & \text { Pharmacopoeia of the People's Republic } \\ & \text { of China } \\ \text { PPL: } & \text { Porcine pancreatic lipase } \\ \text { Rs-AFP and RAP: } & \text { Raphanus Sativus Antifungal Protein } \\ \text { SHR: } & \text { Spontaneously hypertensive rats } \\ \text { TCM: } & \text { Traditional Chinese Medicine. }\end{array}$

\section{Conflict of Interests}

The authors have declared that there is no conflict of interests.

\section{Acknowledgments}

This research was financially supported by the Department of Applied Biology and Chemical Technology, The Hong Kong Polytechnic University, and the Shenzhen Municipal Key Laboratory Advancement Program, Shenzhen, China.

\section{References}

[1] L. Z. Wang and Q. W. He, Chinese Radish, Scientific and Technical Documents Publishing House, Beijing, China, 2005.

[2] R. M. P. Gutiérrez and R. L. Perez, "Raphanus sativus (Radish): their chemistry and biology," The Scientific World Journal, vol. 4, pp. 811-837, 2004.

[3] Chinese Pharmacopoeia Commission, Pharmacopoeia of the People's Republic of China, Chinese Medical Science Press, Beijing, China, 2010.

[4] Z. Zhao and P. Xiao, Encyclopedia of Medicinal Plants, Shanghai World Publishing Corporation, Shanghai, China, 2009-2010.

[5] L. Q. Sui, S. P. Li, and W. H. Lu, "Summarization on the study progress of sanziyangqing decoction in recent ten years," Guiding Journal of Traditional Chinese Medicine and Pharmacology, vol. 12, pp. 103-104, 2006.

[6] Z. Bencao and J. X. Ben, State Administration of Traditional Chinese Medicine, Shanghai Scientific and Technical Publishers, Shanghai, China, 1998.

[7] W.-M. Tang, E. Chan, C.-Y. Kwok et al., "A review of the anticancer and immunomodulatory effects of Lycium barbarum fruit," Inflammopharmacology, vol. 20, pp. 307-314, 2012.
[8] S. W. Chan, S. Li, C. Y. Kwok et al., "Antioxidant activity of Chinese medicinal herbs," Pharmaceutical Biology, vol. 46, no. 9, pp. 587-595, 2008.

[9] E. Chan, J. Y. Y. Chan, J. H. Wu et al., "Serum nitric oxide synthase activity is a novel predictor of impaired vasorelaxation in rats," Clinical and Experimental Pharmacology and Physiology, vol. 39, pp. 894-896, 2012.

[10] J. Y. Chan, A. C. Yuen, R. Y. Chan, and S. W. Chan, "A review of the cardiovascular benefits and antioxidant properties of allicin," Phytotherapy Research, vol. 27, no. 5, pp. 637-646, 2013.

[11] S.-W. Chan, "Panax ginsengRhodiola rosea and Schisandra chinensis," International Journal of Food Sciences and Nutrition, vol. 63, supplement 1, pp. 75-81, 2012.

[12] P. Tan, H. Y. Jiang, and W. H. Lu, "A research review of Raphani Semen," Journal of Practical Traditional Chinese Medicine, vol. 21, pp. 254-255, 2005.

[13] Y. B. Li and S. Jing, "Determination of the total alkaloids in Semen Raphani by acid dye colorimetry," Information on Traditional Chinese Medicine, vol. 27, pp. 8-10, 2010.

[14] A. Bouchereau, J. Hamelin, I. Lamour, M. Renard, and F. Larher, "Distribution of sinapine and related compounds in seeds of Brassica and allied genera," Phytochemistry, vol. 30, no. 6, pp. 1873-1881, 1991.

[15] J. Regenbrecht and D. Strack, "Distribution of 1-sinapoylglucose: choline sinapoyltransferase activity in the brassicaceae," Phytochemistry, vol. 24, no. 3, pp. 407-410, 1985.

[16] W. L. Wang, J. Zhu, Z. D. Li et al., "Hypotensive constituent of Laifuzi (Semen Raphani)," Zhongcaoyao, vol. 18, pp. 101-103, 1987.

[17] L. F. Liu, Y. X. Wang, X. Y. Zhang et al., "Determination of Sinapine in Semen Raphani," Chinese Traditional Patent Medicine, vol. 24, pp. 52-54, 2002.

[18] J. Xing, Y. X. Yuan, and B. M. Feng, "Extraction and high performance liquid chromatographic determination of sinapine in five cruciferous plants," Journal Home of Analytical Science, vol. 28, pp. 523-526, 2012.

[19] M. F. Zhang and Y. Q. Shen, "Antidiarrheal and antiinflammatory effects of sinapine," Pharmacology and Clinics of Chinese Materia Medica, pp. 29-31, 1996.

[20] F. Q. Guo, Q. Li, and R. Q. Gu, "Effects of Sinapine on X-ray induced changes of peripheral blood picture in mice," Journal of Radiation Research and Radiation Processing, vol. 13, pp. 177$180,1995$.

[21] W. Y. Li, Q. Li, F. Q. Guo et al., "DNA damage induced by $\mathrm{X}$-irradiation and reactive oxygen species and the protection against it by sinapine," Acta Phytophysiologica Sinica, vol. 23, pp. 319-323, 1997.

[22] C.-Y. Yang and L. He, "Neuroprotective effects of sinapine on PC12 cells apoptosis induced by sodium dithionite," Chinese Journal of Natural Medicines, vol. 6, no. 3, pp. 205-209, 2008.

[23] B. Matthäus, "Antioxidant activity of extracts obtained from residues of different oilseeds," Journal of Agricultural and Food Chemistry, vol. 50, no. 12, pp. 3444-3452, 2002.

[24] Q. Li and R. Q. Gu, "The effects of Sinapine from Cruciferous plants on the life-span of Drosophila melanogaste," Chinese Journal of Applied and Environmental Biology, pp. 32-35, 1999.

[25] L. He, H.-T. Li, S.-W. Guo et al., "Inhibitory effects of sinapine on activity of acetylcholinesterase in cerebral homogenate and blood serum of rats," China Journal of Chinese Materia Medica, vol. 33, no. 7, pp. 813-815, 2008. 
[26] Q. L. Yan, W. Hua, L. D. Luo et al., "Effect of sinapine on learn and memory disorder of Alzheimer's disease rats and hippocampal cholinergic function," Lishizhen Medicine and Materia Medica Research, vol. 23, pp. 1188-1189, 2012.

[27] Y.-S. Keum, "Regulation of the Keap1/Nrf2 system by chemopreventive sulforaphane: implications of posttranslational modifications," Annals of the New York Academy of Sciences, vol. 1229, no. 1, pp. 184-189, 2011.

[28] S. Giacoppo, M. Galuppo, R. Iori et al., "Protective role of (RS)glucoraphanin bioactivated with myrosinase in an experimental model of multiple sclerosis," CNS Neuroscience \& Therapeutics, pp. 1-8, 2013.

[29] A. F. Abdull Razis, M. Bagatta, G. R. de Nicola, R. Iori, and C. Ioannides, "Intact glucosinolates modulate hepatic cytochrome P450 and phase II conjugation activities and may contribute directly to the chemopreventive activity of cruciferous vegetables," Toxicology, vol. 277, no. 1-3, pp. 74-85, 2010.

[30] P. Q. Kuang, D. Song, Q. P. Yuan et al., "Separation and purification of sulforaphene from radish seeds using macroporous resin and preparative high-performance liquid chromatography," Food Chemistry, vol. 136, pp. 342-347, 2013.

[31] S. J. T. Jackson and K. W. Singletary, "Sulforaphane inhibits human MCF-7 mammary cancer cell mitotic progression and tubulin polymerization," Journal of Nutrition, vol. 134, no. 9, pp. 2229-2236, 2004.

[32] M. C. Ramirez and K. Singletary, "Regulation of estrogen receptor $\alpha$ expression in human breast cancer cells by sulforaphane," Journal of Nutritional Biochemistry, vol. 20, no. 3, pp. 195-201, 2009.

[33] J. D. Brooks, V. G. Paton, and G. Vidanes, "Potent induction of phase 2 enzymes in human prostate cells by sulforaphane," Cancer Epidemiology Biomarkers and Prevention, vol. 10, no. 9, pp. 949-954, 2001.

[34] A. Gibbs, J. Schwartzman, V. Deng, and J. Alumkal, "Sulforaphane destabilizes the androgen receptor in prostate cancer cells by inactivating histone deacetylase 6," Proceedings of the National Academy of Sciences of the United States of America, vol. 106, no. 39, pp. 16663-16668, 2009.

[35] N.-A. Pham, J. W. Jacobberger, A. D. Schimmer, P. Cao, M. Gronda, and D. W. Hedley, "The dietary isothiocyanate sulforaphane targets pathways of apoptosis, cell cycle arrest, and oxidative stress in human pancreatic cancer cells and inhibits tumor growth in severe combined immunodeficient mice," Molecular Cancer Therapeutics, vol. 3, no. 10, pp. 1239-1248, 2004.

[36] M. Wang, Y.-Q. Li, N. Zhong, J. Chen, X.-Q. Xu, and M.-B. Yuan, "Induction of uridine 5 '-diphosphate-glucuronosyltransferase gene expression by sulforaphane and its mechanism: experimental study in human colon cancer cells," National Medical Journal of China, vol. 85, no. 12, pp. 819-824, 2005.

[37] C. Fimognari, M. Nüsse, R. Cesari, R. Iori, G. Cantelli-Forti, and P. Hrelia, "Growth inhibition, cell-cycle arrest and apoptosis in human T-cell leukemia by the isothiocyanate sulforaphane," Carcinogenesis, vol. 23, no. 4, pp. 581-586, 2002.

[38] I. Misiewicz, K. Skupińska, E. Kowalska, J. Lubiński, and T. Kasprzycka-Guttman, "Sulforaphane-mediated induction of a phase 2 detoxifying enzyme $\mathrm{NAD}(\mathrm{P}) \mathrm{H}$ :quinone reductase and apoptosis in human lymphoblastoid cells," Acta Biochimica Polonica, vol. 51, no. 3, pp. 711-721, 2004.

[39] M. Pan, R. Huang, J. Tan et al., "Induction of phase II metabolic enzymes by sulforaphene in human immortalized hepatocytes,"
Information on Traditional Chinese Medicine, vol. 29, pp. 13-15, 2012.

[40] Y. Zhang, P. Talalay, C.-G. Cho, and G. H. Posner, "A major inducer of anticarcinogenic protective enzymes from broccoli: isolation and elucidation of structure," Proceedings of the National Academy of Sciences of the United States of America, vol. 89, no. 6, pp. 2399-2403, 1992.

[41] A. T. Dinkova-Kostova, J. W. Fahey, A. L. Benedict et al., "Dietary glucoraphanin-rich broccoli sprout extracts protect against UV radiation-induced skin carcinogenesis in SKH-1 hairless mice," Photochemical and Photobiological Sciences, vol. 9, no. 4, pp. 597-600, 2010.

[42] G. Ivánovics and S. Horváth, "Raphanin, an antibacterial principle of the radish (Raphanus sativus)," Nature, vol. 160, no. 4061, pp. 297-298, 1947.

[43] J. Malíková, J. Swaczynová, Z. Kolář, and M. Strnad, “Anticancer and antiproliferative activity of natural brassinosteroids," Phytochemistry, vol. 69, no. 2, pp. 418-426, 2008.

[44] A. Rosado-Abón, G. de Dios-Bravo, R. Rodríguez-Sotres et al., "Synthesis and plant growth promoting activity of dinorcholanic lactones bearing the $5 \alpha$-hydroxy-6-oxo moiety," The Journal of Steroid Biochemistry and Molecular Biology, vol. 134, pp. 45-50, 2013.

[45] W. J. Meudt, "Investigations on the mechanism of the brassinosteroid response. VI. Effect of brassinolide on gravitropism of bean hypocotyls," Plant Physiology, vol. 83, pp. 195-198, 1987.

[46] L. R. Galagovsky, E. G. Gros, and J. A. Ramírez, "Synthesis and bioactivity of natural and C-3 fluorinated biosynthetic precursors of 28-homobrassinolide," Phytochemistry, vol. 58, no. 6, pp. 973-980, 2001.

[47] D. Y. Hou, R. H. Hui, T. C. Li et al., "Determination of fatty acids and octadecatrienoic acid in radish seed," Journal of Chinese Mass Spectrometry Society, vol. 32, pp. 108-111, 2011.

[48] W. G. Gao and G. L. Zhao, "Optimal extraction process and composition analysis of radish seed oil," Food Science, vol. 33, pp. 159-163, 2012.

[49] P. Sengupta and B. R. Roy, "Studies on the composition and characteristics of Indian radish seed oil," Journal of Food Science and Technology-Mysore, vol. 19, pp. 254-257, 1982.

[50] G. L. Zhao, R. Hao, H. You et al., "Fatty acid composition and antioxidant activity of 8 kinds of radish seed oil," China Oils and Fats, vol. 36, pp. 73-76, 2011.

[51] S. Uluata and N. Özdemir, "Antioxidant activities and oxidative stabilities of some unconventional oilseeds," Journal of the American Oil Chemists' Society, vol. 89, pp. 551-559, 2012.

[52] F. R. G. Terras, H. M. E. Schoofs, M. F. C. de Bolle et al., "Analysis of two novel classes of plant antifungal proteins from radish (Raphanus sativus L.) seeds," Journal of Biological Chemistry, vol. 267, no. 22, pp. 15301-15309, 1992.

[53] F. Fant, W. Vranken, W. Broekaert, and F. Borremans, "Determination of the three-dimensional solution structure of Raphanus sativus antifungal protein 1 by $1 \mathrm{H}$ NMR," Journal of Molecular Biology, vol. 279, no. 1, pp. 257-270, 1998.

[54] C. Landon, F. Vovelle, P. Sodano, and A. Pajon, “The active site of drosomycin, a small insect antifungal protein, delineated by comparison with the modeled structure of Rs-AFP2, a plant antifungal protein," The Journal of Peptide Research, vol. 56, no. 4, pp. 231-238, 2000.

[55] J. H. Park, H.-K. Shin, and C.-W. Hwang, "New antimicrobial activity from Korean radish seeds (Raphanus sativus L.)," Journal of Microbiology and Biotechnology, vol.11, no. 2, pp. 337341, 2001. 
[56] M. Xue, Z. J. Wang, Y. J. Yan et al., "Microwave technique extraction and determination of total flavonoids and polysaccharides from Semen Raphani," Journal of Shihezi University (Natural Science), vol. 23, pp. 155-157, 2005.

[57] Y. Tsumuraya, Y. Hashimoto, and S. Yamamoto, "An L-arabinoD-galactan and an L-arabino-D-galactan-containing proteoglycan from radish (Raphanus sativus) seeds," Carbohydrate Research, vol. 161, no. 1, pp. 113-126, 1987.

[58] Y. Mizushina, T. Takeuchi, F. Sugawara, and H. Yoshida, "Anticancer targeting telomerase inhibitors: $\beta$-rubromycin and oleic acid," Mini Reviews in Medicinal Chemistry, vol. 12, no. 11, pp. 1135-1143, 2012.

[59] L.-M. Shi, H.-T. Ge, X.-Q. Kong et al., "Effects of gamma linolenic acid on atherosclerosis induced by cholesterol-rich diet in rats," China Journal of Chinese Materia Medica, vol. 33, no. 23, pp. 2808-2812, 2008.

[60] Y. Dai, H. H. Yan, and F. Wang, "Effects of $\alpha$-linolenic acid and $\gamma$-linolenic acid on the blood-lipid levels in hyperlipidemia people," Progress in Modern Biomedicine, vol. 9, pp. 4492-4495, 2009.

[61] J. E. Hunter, J. Zhang, and P. M. Kris-Etherton, "Cardiovascular disease risk of dietary stearic acid compared with trans, other saturated, and unsaturated fatty acids: a systematic review," The American Journal of Clinical Nutrition, vol. 91, no. 1, pp. 46-63, 2010.

[62] J. R. Sargent, K. Coupland, and R. Wilson, "Nervonic acid and demyelinating disease," Medical Hypotheses, vol. 42, no. 4, pp. 237-242, 1994.

[63] E. Oda, K. Hatada, J. Kimura, Y. Aizawa, P. V. Thanikachalam, and K. Watanabe, "Relationships between serum unsaturated fatty acids and coronary risk factors. Negative relations between nervonic acid and obesity-related risk factors," International Heart Journal, vol. 46, no. 6, pp. 975-985, 2005.

[64] S. V. Veeresh Babu, B. Veeresh, A. A. Patil, and Y. B. Warke, "Lauric acid and myristic acid prevent testosterone induced prostatic hyperplasia in rats," European Journal of Pharmacology, vol. 626, no. 2-3, pp. 262-265, 2010.

[65] G. S. Dhaunsi, J. Kaur, K. Alsaeid, R. B. Turner, and M. S. Bitar, "Very long chain fatty acids activate NADPH oxidase in human dermal fibroblasts," Cell Biochemistry and Function, vol. 23, no. 1, pp. 65-68, 2005.

[66] Z.-H. Yang, H. Miyahara, and A. Hatanaka, "Chronic administration of palmitoleic acid reduces insulin resistance and hepatic lipid accumulation in KK-Ay Mice with genetic type 2 diabetes," Lipids in Health and Disease, vol. 10, article 120, 2011.

[67] A. Kamal-Eldin and L.-Å. Appelqvist, "The chemistry and antioxidant properties of tocopherols and tocotrienols," Lipids, vol. 31, no. 7, pp. 671-701, 1996.

[68] S. Nemmiche, D. Chabane-Sari, and P. Guiraud, "Role of $\alpha$ tocopherol in cadmium-induced oxidative stress in Wistar rat's blood, liver and brain," Chemico-Biological Interactions, vol. 170, no. 3, pp. 221-230, 2007.

[69] L. Lazzeri, R. Tacconi, and S. Palmieri, "In vitro activity of some glucosinolates and their reaction products toward a population of the nematode Heterodera schachtii," Journal of Agricultural and Food Chemistry, vol. 41, no. 5, pp. 825-829, 1993.

[70] M. Benn, "Glucosinolates," Pure and Applied Chemistry, vol. 49, pp. 197-210, 1977.

[71] A. M. Bones and J. T. Rossiter, "The myrosinase-glucosinolate system, its organisation and biochemistry," Physiologia Plantarum, vol. 97, no. 1, pp. 194-208, 1996.
[72] Y. Hu, H. Liang, Q. Yuan, and Y. Hong, "Determination of glucosinolates in 19 Chinese medicinal plants with spectrophotometry and high-pressure liquid chromatography," Natural Product Research, vol. 24, no. 13, pp. 1195-1205, 2010.

[73] J. W. Fahey, Y. Zhang, and P. Talalay, "Broccoli sprouts: an exceptionally rich source of inducers of enzymes that protect against chemical carcinogens," Proceedings of the National Academy of Sciences of the United States of America, vol. 94, no. 19, pp. 10367-10372, 1997.

[74] C. Nastruzzi, R. Cortesi, E. Esposito et al., "In vitro antiproliferative activity of isothiocyanates and nitriles generated by myrosinase-mediated hydrolysis of glucosinolates from seeds of cruciferous vegetables," Journal of Agricultural and Food Chemistry, vol. 48, no. 8, pp. 3572-3575, 2000.

[75] H. Liang, Q.-P. Yuan, H.-R. Dong, Z.-M. Qian, and Y.-M. Liu, "Comparison of sulforaphane content in seeds of Cruciferous plant," Chinese Pharmaceutical Journal, vol. 39, no. 12, pp. 898909, 2004.

[76] J. W. Fahey and P. Talalay, "Antioxidant functions of sulforaphane: a potent inducer of phase II detoxication enzymes," Food and Chemical Toxicology, vol. 37, no. 9-10, pp. 973-979, 1999.

[77] C.-T. Yeh and G.-C. Yen, "Chemopreventive functions of sulforaphane: a potent inducer of antioxidant enzymes and apoptosis," Journal of Functional Foods, vol. 1, no. 1, pp. 23-32, 2009.

[78] P. Abassi, F. Abassi, F. Yari, M. Hashemi, and S. Nafisi, "Study on the interaction of sulforaphane with human and bovine serum albumins," Journal of Photochemistry and Photobiology B, vol. 122, pp. 61-67, 2013.

[79] C.-J. Yang, C. Zhang, Y.-N. Lu, J.-Q. Jin, and X.-L. Wang, “The mechanisms of brassinosteroids' action: from signal transduction to plant development," Molecular Plant, vol. 4, no. 4, pp. 588-600, 2011.

[80] A. Bajguz and A. Tretyn, "The chemical characteristic and distribution of brassinosteroids in plants," Phytochemistry, vol. 62, no. 7, pp. 1027-1046, 2003.

[81] J. Schmidt, T. Yokota, G. Adam, and N. Takahashi, "Castasterone and brassinolide in Raphanus sativus seeds," Phytochemistry, vol. 30, no. 1, pp. 364-365, 1991.

[82] J. Schmidt, T. Yokota, B. Spengler, and G. Adam, "28homoteasterone, a naturally occurring brassinosteroid from seeds of Raphanus sativus," Phytochemistry, vol. 34, no. 2, pp. 391-392, 1993.

[83] T. Noguchi, S. Fujioka, S. Choe et al., "Biosynthetic pathways of brassinolide in Arabidopsis," Plant Physiology, vol. 124, no. 1, pp. 201-209, 2000.

[84] M. Umamaheswari, M. P. Ajith, K. Asokkumar et al., "In vitro angiotensin converting enzyme inhibitory and antioxidant activities of seed extract of Raphanus sativus Linn," Central European Journal of Experimental Biology, vol. 1, pp. 11-17, 2012.

[85] C. W. Wan, C. N. Wong, W. K. Pin et al., "Chlorogenic acid exhibits cholesterol lowering and fatty liver attenuating properties by up-regulating the gene expression of PPAR- $\alpha$ in hypercholesterolemic rats induced with a high-cholesterol diet," Phytotherapy Research, vol. 27, no. 4, pp. 545-551, 2013.

[86] C. Prohaska, K. Pomazal, and I. Steffan, "Determination of Ca, $\mathrm{Mg}, \mathrm{Fe}, \mathrm{Cu}$, and $\mathrm{Zn}$ in blood fractions and whole blood of humans by ICP-OES,' Fresenius' Journal of Analytical Chemistry, vol. 367, no. 5, pp. 479-484, 2000.

[87] D. M. Lloyd-Jones, E. P. Leip, M. G. Larson, R. S. Vasan, and D. Levy, "Novel approach to examining first cardiovascular events 
after hypertension onset," Hypertension, vol. 45, no. 1, pp. 39-45, 2005.

[88] L. G. Ogden, J. He, E. Lydick, and P. K. Whelton, "Long-term absolute benefit of lowering blood pressure in hypertensive patients according to the JNC VI risk stratification," Hypertension, vol. 35, no. 2, pp. 539-543, 2000.

[89] H. Y. Zhang, D. Q. Han, W. Liu et al., "Screening the antihypertentive fractions from Raphani Semen," Journal of Changchun University of Traditional Chinese Medicine, vol. 28, pp. 11-12, 2012.

[90] T. Y. Li, T. G. Li, G. X. Zhang et al., "Experimental study of hypotensive effect of soluble Semen Raphani alkaloids in spontaneous hypertensive rats," World Journal of Integrated Traditional and Western Medicine, vol. 2, pp. 25-28, 2007.

[91] A. Y. Song, B. Shi, W. Wang et al., "Effects of Semen Raphani on cardiohemodynamics in anesthetized dogs," Acta Chinese Medicine and Pharmacology, pp. 48-50, 1990.

[92] M. N. Ghayur and A. H. Gilani, "Radish seed extract mediates its cardiovascular inhibitory effects via muscarinic receptor activation," Fundamental and Clinical Pharmacology, vol. 20, no. 1, pp. 57-63, 2006.

[93] C. Y. Han, F. S. Ding, and L. Wang, "Curative effect of Qingxuanjianyia tablets on hypertension," Chinese Traditional Patent Medicine, vol. 23, pp. 193-195, 2001.

[94] H. Ge, J. X. Xie, S. Y. Wang et al., "The blood pressure lowering effect of Qingxuan: compared with nitrendipine," Chinese Pharmaceutical Journal, vol. 35, no. 3, pp. 202-203, 2000.

[95] A. B. R. Thomson, A. de Pover, M. Keelan, E. Jarocka-Cyrta, and M. T. Clandinin, "Inhibition of lipid absorption as an approach to the treatment of obesity," in Methods in Enzymology, pp. 344, Academic Press, San Diego, Calif, USA, 1997.

[96] C.-D. Zheng, Y.-Q. Duan, J.-M. Gao, and Z.-G. Ruan, "Screening for anti-lipase properties of 37 traditional Chinese medicinal herbs," Journal of the Chinese Medical Association, vol. 73, no. 6, pp. 319-324, 2010.

[97] E. Ferrannini, G. Buzzigoli, R. Bonadonna et al., "Insulin resistance in essential hypertension," The New England Journal of Medicine, vol. 317, no. 6, pp. 350-357, 1987.

[98] S.-H. Ko, W. Cao, and Z. Liu, "Hypertension management and microvascular insulin resistance in diabetes," Current Hypertension Reports, vol. 12, no. 4, pp. 243-251, 2010.

[99] X. L. Liang, A. M. Yua, M. J. Zhu et al., "Effects of Coptidis Rhizoma, Hirudo seu Whitmania, Raphani Semen on the receptor of hepatic membrane from the model of hypertensive insulin resistance rats," Chinese Journal of Geriatric Care, vol. 4 , pp. 21-23, 2006.

[100] N. Bernardini, C. Ippolito, C. Segnani et al., "Histopathology in gastrointestinal neuromuscular diseases: methodological and ontological issues," Advances in Anatomic Pathology, vol. 20, pp. 17-31, 2013.

[101] J. Wang, Y. Kong, and H. Wang, "The effect of radish seed on smooth muscles of isolated guinea pig ileum," Journal of Dalian University, vol. 21, pp. 80-81, 2000.

[102] M. N. Ghayur, A. H. Gilani, and P. J. Houghton, "Species differences in the gut stimulatory effects of radish seeds," Journal of Pharmacy and Pharmacology, vol. 57, no. 11, pp. 1493-1501, 2005.

[103] L. Xue, P. Tan, and W. H. Lu, "The effects of digestive system of different processed products of Semen Raphani and their acute toxicity," Journal of Shandong University of Traditional Chinese Medicine, vol. 30, pp. 74-75, 2006.
[104] R. Liu, Y. Lu, M. J. Liu, J. Liu, and Y. Cao, “The effects of different radish seed extractive on defection of mice with experimental constipation," Modern Traditional Chinese Medicine, vol. 30, pp. 59-60, 2010.

[105] P. Tan, L. Xue, W. H. Lu et al., "The effects of respiratory system of different processed products of Semen Raphani," Shandong Journal of Traditional Chinese Medicine, vol. 24, pp. 300-302, 2005.

[106] C. Ratanasethkul, C. Riddell, R. E. Salmon, and J. B. O’Neil, "Pathological changes in chickens, ducks and turkeys fed high levels of rapeseed oil," Canadian Journal of Comparative Medicine, vol. 40, no. 4, pp. 360-369, 1976.

[107] L. C. Dolan, R. A. Matulka, and G. A. Burdock, "Naturally occurring food toxins," Toxins, vol. 2, no. 9, pp. 2289-2332, 2010.

[108] E. Bozcali, Ö. Süzer, H. N. Gürsoy, P. Atukeren, and K. M. Gümüstas, "Effects of erucic acid supplemented feeding on chronic doxorubucin toxicity in rats," International Journal of Clinical and Experimental Medicine, vol. 2, no. 4, pp. 337-347, 2009. 


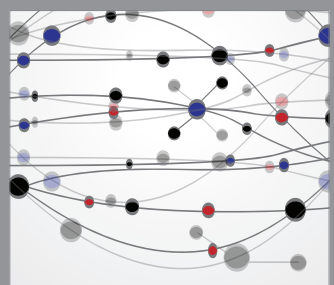

The Scientific World Journal
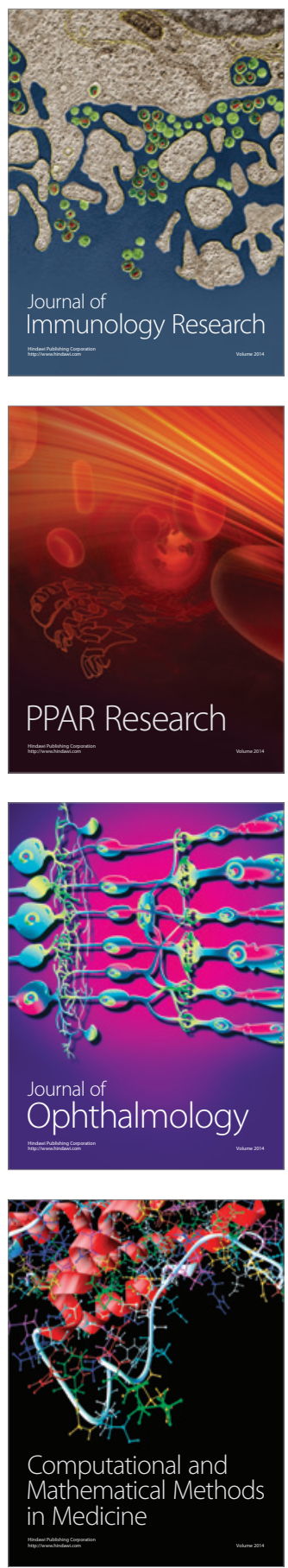

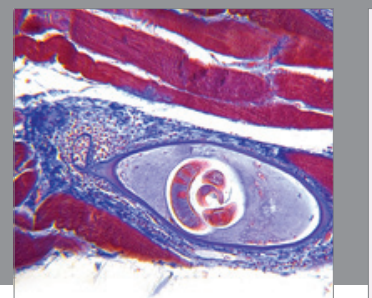

Gastroenterology

Research and Practice
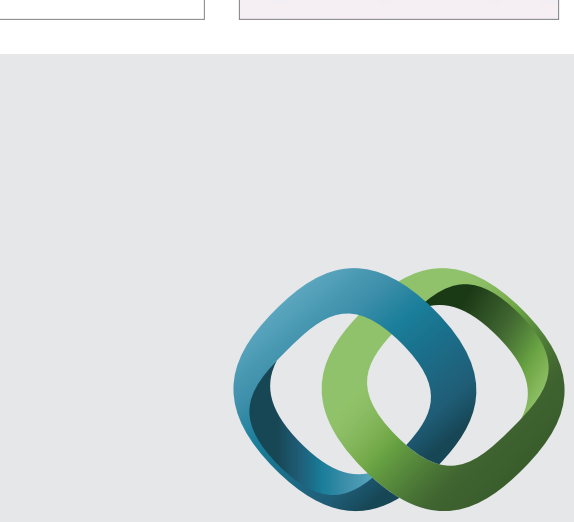

\section{Hindawi}

Submit your manuscripts at

http://www.hindawi.com
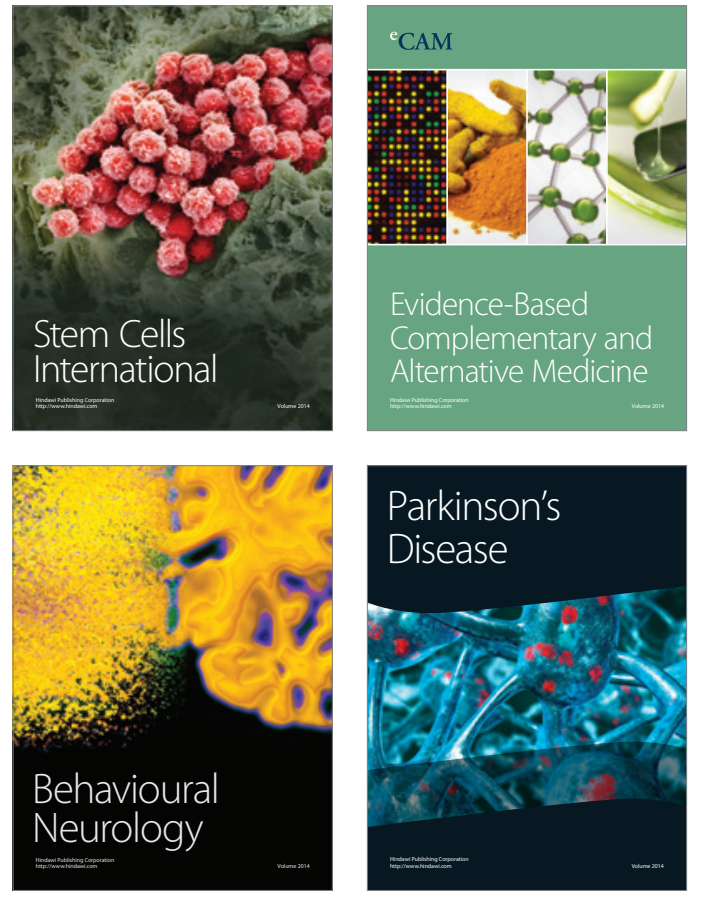
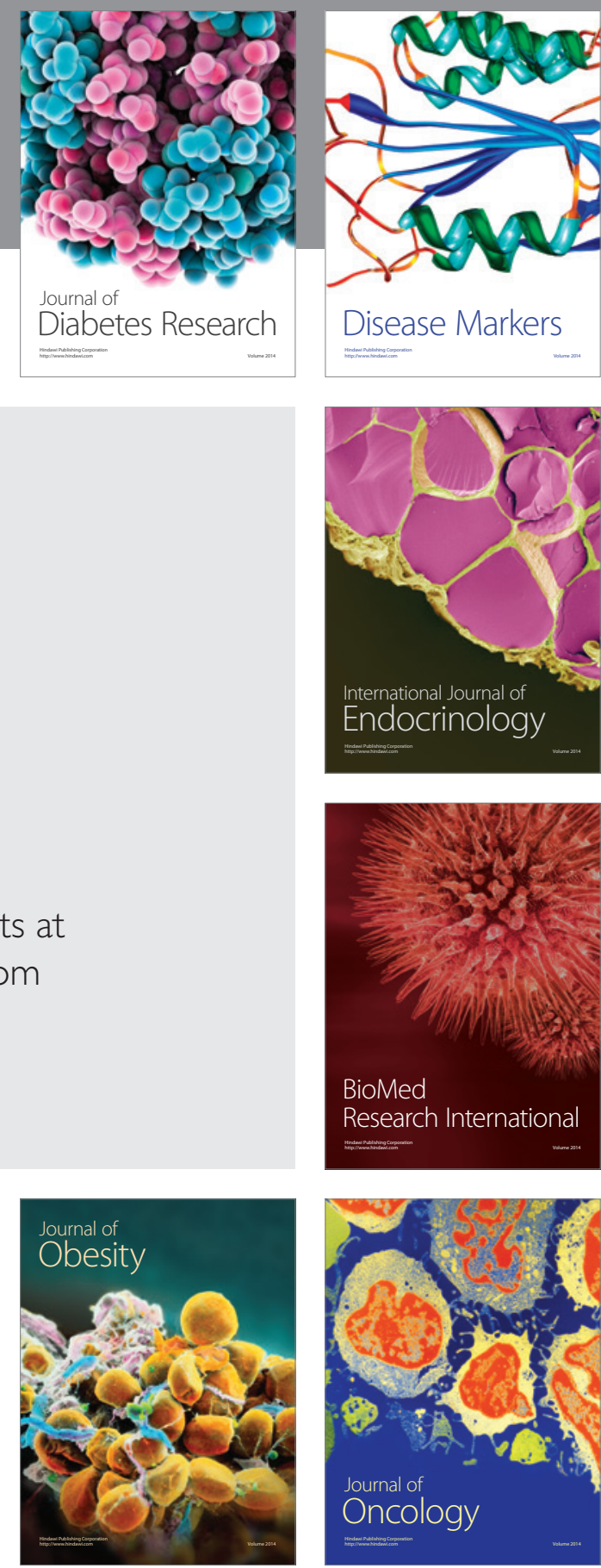

Disease Markers
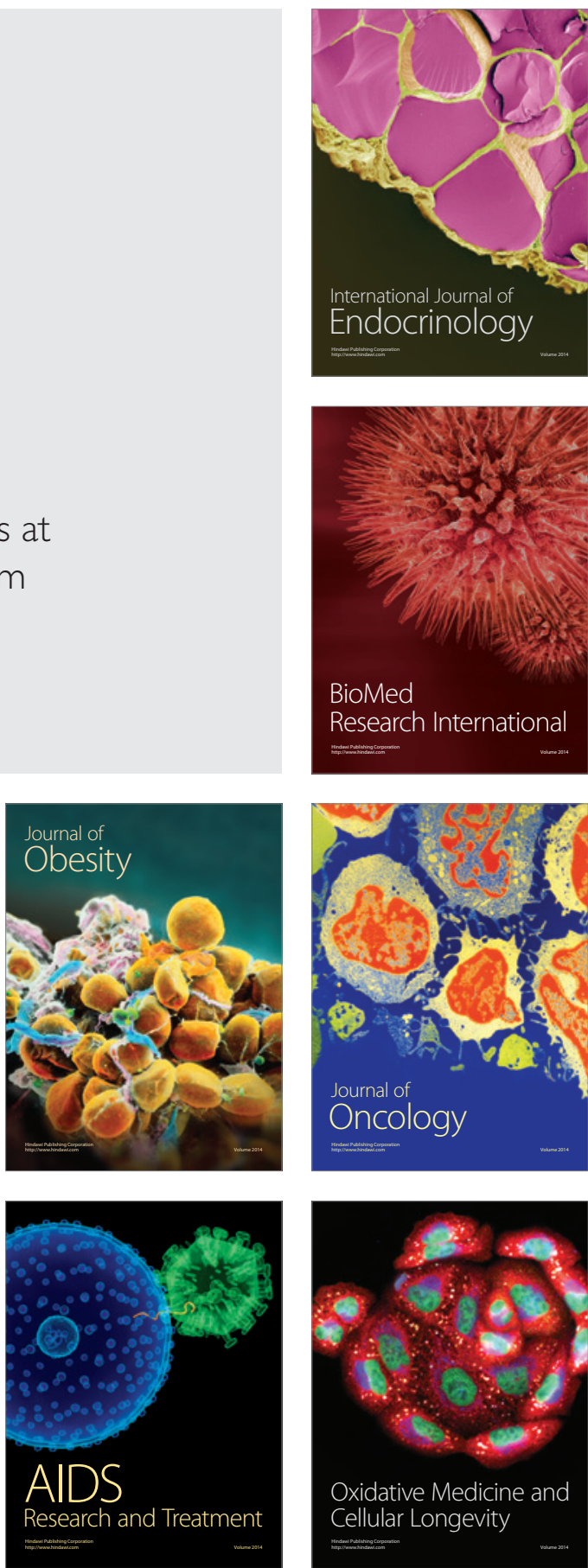